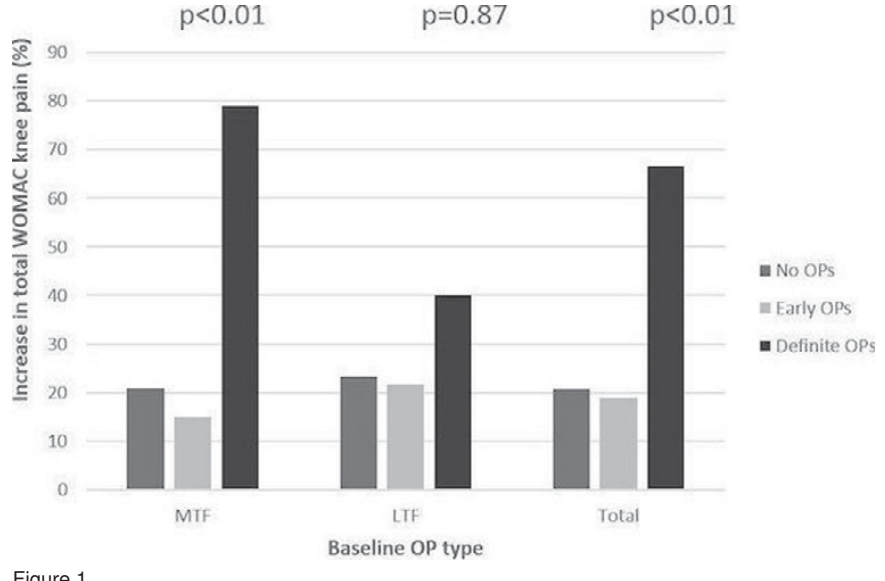

Figure 1

Disclosure of Interest: None declared

DOI: 10.1136/annrheumdis-2017-eular.1060

\section{OP0170 LEPTIN AND ADIPONECTIN MEDIATE THE ASSOCIATION BETWEEN BODY MASS INDEX AND HAND AND KNEE OSTEOARTHRITIS}

A. Veenbrink ${ }^{1}$, F. Kroon ${ }^{2}$, R. de Mutsert ${ }^{3}$, W. Visser ${ }^{2}$, S. le Cessie ${ }^{3}$,

F. Rosendaal ${ }^{3}$, M. Kloppenburg ${ }^{2} .{ }^{1}$ Medicine, Universiteit Utrecht, Utrecht;

${ }^{2}$ Rheumatology; ${ }^{3}$ Clinical Epidemiology, Leids Universitair Medisch Centrum, Leiden, Netherlands

Background: Associations between adiposity and osteoarthritis (OA) in nonweight-bearing joints suggest that besides mechanical factors also systemic influences contribute to OA. Systemically active substances secreted by adipose tissue, including leptin and adiponectin, are hypothesized to play a role in OA.

Objectives: To examine whether leptin and adiponectin mediate the association between body mass index (BMI) and hand and knee OA.

Methods: Cross-sectional data of a population-based study were used. Participants completed questionnaires and underwent standardized physical examination of hands and knees to define OA according to clinical American College of Rheumatology criteria. Fasting serum leptin and adiponectin were measured with immunoassays. Potential mediation was investigated using the Baron and Kenny framework. Four assumptions were investigated: associations between (1) $\mathrm{BMI}$ and $\mathrm{OA}$ (pathway $C$ ), (2) BMl and adipokines (pathway $A$ ), (3) adipokines and $\mathrm{OA}$ (pathway $B$ ), and (4) attenuation of the total association between BMI and OA after including adipokines (pathway $C^{\prime}$ ). No exposure-mediator interaction and mediator-outcome confounding was assumed. Assumptions were investigated using logistic and linear regression analyses as appropriate. Odds Ratios (ORs) were calculated per standard deviation (SD) difference in BMI, and per ten and five units difference in leptin and adiponectin, respectively. Percentage mediation with $95 \%$ confidence intervals (Cls) was estimated, only when all four assumptions were fulfilled. Models were adjusted for age, ethnicity and education, and stratified by sex. Results: In 6462 participants (56\% women, median age 56 years (range 45-65), mean BMI $26.3 \mathrm{~kg} / \mathrm{m}^{2}$ ), prevalence of hand OA, knee OA and combined hand and knee OA were $8 \%, 10 \%$ and $4 \%$, respectively. Median leptin and adiponectin concentrations were $7.1 \mathrm{ug} / \mathrm{L}$ (range $0.9-60.9)$ and $6.0 \mathrm{mg} / \mathrm{L}(0.5-23.7)$ in men, and $19.1 \mathrm{ug} / \mathrm{L}(0.5-262.0)$ and $10.5 \mathrm{mg} / \mathrm{L}(0.5-98.6)$ in women. BMI was positively associated with $\mathrm{OA}$ presence and serum leptin in both men and women (Table). A negative association was observed between $\mathrm{BMI}$ and serum adiponectin $(-0.73$ $\mathrm{mg} / \mathrm{L}$ per SD BMI, 95\% Cl $-0.55 ;-0.91)$. Leptin was positively associated with most OA types, except knee OA in men. Leptin partially mediated the association of $\mathrm{BMI}$ with hand $\mathrm{OA}$ in men $(9 \%$ mediation, $95 \% \mathrm{Cl} 5 ; 17)$ and women $(30 \%$, $13 ; 198)$, and the association of BMI with knee OA in women $(15 \%, 12 ; 21)$. Similar analyses for adiponectin revealed a negative association of adiponectin with hand $\mathrm{OA}$ in men and partial mediation of the association of BMI with hand OA in men $(19 \%, 12 ; 37)$, whereas mediation was absent in other subgroups.

Conclusions: Leptin partially mediated the association of BMI and hand OA in both men and women, as did adiponectin in men. In addition, mediation by leptin

\begin{tabular}{|c|c|c|c|c|c|c|}
\hline MEN & $\begin{array}{l}\text { Pathway A } \\
\text { BMI-log leptin * } \\
\beta(95 \% \mathrm{Cl})\end{array}$ & & $\begin{array}{l}\text { Pathway B } \\
\text { Leptin - OA } \\
\text { OR }(95 \% \text { CI) }\end{array}$ & $\begin{array}{l}\text { PathwayC } \\
\text { BMI-OA } \\
\text { OR }(95 \% \text { CI) }\end{array}$ & $\begin{array}{l}\text { Pathway } C^{\prime} \\
\text { BMI-OA } \\
\text { OR }\left(95 \% C^{\prime}\right)\end{array}$ & $\begin{array}{l}\text { Mediation } \\
\%(95 \% \text { C1) }\end{array}$ \\
\hline \multirow[t]{3}{*}{ SD BMI: 3.72} & $1.70(1.64-1.77)$ & Hand $\mathrm{OA}$ & $1.30(1.13-1.50)$ & $1.39(1.18-1.64)$ & $1.34(1.06-1.70)$ & $8.6(5.4-17.2)$ \\
\hline & & Knee OA & $1.14(0.98-1.43)$ & $1.25(1.06-1.48)$ & & \\
\hline & & Hand and knee $O A$ & $1.28(1.07-1.52)$ & $1.59(1.31-1.93)$ & $1.82(1.39-2.39)$ & \\
\hline \multirow[t]{2}{*}{ WOMEN } & $\begin{array}{l}\text { Pathway } A \\
\text { BMI- } \log \text { leptin* }\end{array}$ & & $\frac{\text { Pathway } B}{\text { Leptin - OA }}$ & $\frac{\text { Pathway C }}{\text { BMI-OA }}$ & $\frac{\text { Pathway } C^{\prime}}{B M I-O A}$ & Mediation \\
\hline & $\beta(95 \% \mathrm{Cl})$ & & OR (95\% CI) & OR $(95 \% \mathrm{CI})$ & OR $\left(95 \% C_{C}\right)$ & $\%(95 \% \mathrm{Cl})$ \\
\hline \multirow[t]{3}{*}{ SD BMI: 4.88} & $1.82(1.77-1.88)$ & Hand $O A$ & $1.08(1.01-1.15)$ & $1.18(1.01-1.37)$ & $1.12(0.89-1.40)$ & $30.3(13.3-198.2)$ \\
\hline & & Knee OA & $1.21(1.14-1.29)$ & $1.62(1.42-1.85)$ & $1.50(1.25-1.81)$ & $15.4(11.7-21.3)$ \\
\hline & & Hand and knee $O A$ & $1.13(1.05-1.22)$ & $1.48(1.26-1.74)$ & $1.55(1.25-1.93)$ & \\
\hline
\end{tabular}

for the association of $\mathrm{BMI}$ and knee $\mathrm{OA}$ was demonstrated in women. These findings suggest that systemic mediators contribute to hand $\mathrm{OA}$, and to a lesser extent to knee OA.

Disclosure of Interest: None declared

DOI: 10.1136/annrheumdis-2017-eular.3394

\section{OP0171 SIGNAL INTENSITY ALTERATION WITHIN INFRAPATELLAR FAT PAD PREDICTS TOTAL KNEE ARTHROPLASTY WITHIN FOUR YEARS: DATA FROM THE OSTEOARTHRITIS INITIATIVE}

K. Wang ${ }^{1,2}$, C. Ding ${ }^{1,2,3,4}$, M.J. Hannon ${ }^{5}$, Z. Chen ${ }^{2,6}$, C. Kwoh ${ }^{7}$, D.J. Hunter ${ }^{8}$. ${ }^{1}$ Department of Rheumatology, Arthritis Research Institute, 1st Affiliated Hospital of Anhui Medical University, Hefei, China; ${ }^{2}$ Menzies Institute for Medical Research, Hobart; ${ }^{3}$ Royal North Shore Hospital and Institute of Bone and Joint Research, Kolling Institute, University of Sydney, Sydney, Australia;

${ }^{4}$ Translational Research Centre, Academy of Orthopedics, School of Basic Medical Sciences, Southern Medical University, Guangzhou, China; ${ }^{5}$ Division of Rheumatology and Clinical Immunology, University of Pittsburgh School of Medicine, Pittsburgh, United States; ${ }^{6}$ School of Mathematics and Information Science, Nanjing Normal University of Special Education, Nanjing, China; ${ }^{7}$ University of Arizona Arthritis Center\& Division of Rheumatology, University of Arizona College of Medicine, Tucson, United States; ${ }^{8}$ Department of Rheumatology, Royal North Shore Hospital and Institute of Bone and Joint Research, Kolling Institute, University of Sydney, Sydney, Australia

Background: Osteoarthritis $(\mathrm{OA})$ is a common joint disease that frequently affects the knee and is the leading cause of total knee arthroplasty (TKA) in Western countries. The most common reason for TKA is to ease pain and disability. Investigation on prognostic factors associated with TKA could be a possible way to find therapeutic targets to slow disease progression and delay the time for knee replacement.

Objectives: To investigate whether infrapatellar fat pad (IPFP) signal intensity (SI) alteration predicts the occurrence of TKA in patients with knee OA over 4 years.

Methods: Participants with symptomatic knee OA were selected from the Osteoarthritis Initiative (OAI) study. Case knees $(n=127)$ were defined as those that received TKA during 4 years follow-up visit. They were matched by gender, age and radiographic status measured at baseline with a control knee. We used T2 weighted MR images to measure IPFP SI alteration using a newly developed algorithm in MATLAB. The measurements were assessed at OAI baseline (BL), T0 (the visit when TKA was reported), 1 year prior to T0 (T1). Conditional logistic regression was used to assess the relationship between cases and control knees and assess the risk of TKA in regard to SI alteration.

Results: Participants $(n=237)$ were mostly female $(57 \%)$, with average age of $63.7 \pm 8.5$ years old and mean BMI of $29.5 \pm 4.7 \mathrm{~kg} / \mathrm{m}^{2}$. In multivariable analysis, standard deviation of IPFP SI [sDev (IPFP)] and the ratio of high SI region volume to whole IPFP volume [Percentage $(\mathrm{H})]$ measured at $\mathrm{BL}$ were significantly associated with TKA after adjustment for BMI, knee bending activities, selfreported knee injury and surgery history (HR: $3.5,95 \% \mathrm{Cl} 1.1$ to 11.4 ; HR: 8.9, $95 \% \mathrm{Cl} 1.2$ to 67.2 ). IPFP SI alterations measured at $\mathrm{T} 1$ including sDev (IPFP), Percentage $(\mathrm{H})$ and clustering effect of high SI [Clustering factor $(\mathrm{H})$ ] were significantly associated with TKA (HR: $4.0,95 \% \mathrm{Cl} 1.2$ to 13.2 ; HR 10.9 , $95 \% \mathrm{Cl} 1.9,63.6 ; \mathrm{HR}: 1.8,95 \% \mathrm{Cl} 1.1$ to 2.9 ). All measurements including mean value of IPFP SI [Mean (IPFP)], sDev (IPFP), mean value of IPFP high SI [Mean $(H)$ ], standard deviation of IPFP high SI [sDev $(H)$ ], median value of IPFP high SI [Median $(H)$ ], upper quartile value of IPFP high SI [UQ $(H)]$, Percentage $(H)$, Clustering factor $(\mathrm{H})$ were significantly associated with TKA at T0.

Conclusions: IPFP SI is an important predictor for TKA in knee OA patients. Targeting IPFP SI could be a potential way to reduce the need for future TKA. Acknowledgements: Special thanks go to the participants who made this study possible, the OAI investigators, staff, participants and the funding of POMA study. Disclosure of Interest: None declared

DOI: 10.1136/annrheumdis-2017-eular.1163

\section{THURSDAY, 15 JUNE 2017 Cellular drivers of inflammation in rheumatic disease}

\section{OP0172 EXPANDED T-CELL CLONES PRESENT IN SYNOVIUM AT ONSET OF RHEUMATOID ARTHRITIS ARE ALREADY PRESENT IN THE SYNOVIUM IN THE SEROPOSITIVE "AT RISK" STAGE}

G. Balzaretti ${ }^{1}, 2$, P. Klarenbeek ${ }^{1}$, M. de Hair ${ }^{1}$, M. Doorenspleet ${ }^{1}$, B. van Schaik ${ }^{3}$ M. van de Sande ${ }^{1}$, D. Gerlag ${ }^{1,4}$, A. van Kampen ${ }^{3}$, F. Baas ${ }^{5}$, P.P. Tak ${ }^{1,6}$, N. de Vries ${ }^{1} .{ }^{1}$ Clinical Immunology and Rheumatology; ${ }^{2}$ Experimental Immunology; ${ }^{3}$ Clinical Epidemiology, Biostatistics and Bioinformatics, AMC, Amsterdam, Netherlands: ${ }^{4}$ Clinical Unit Cambridge, GlaxoSmithKline, Cambridge, United Kingdom; ${ }^{5}$ Genome Analysis, AMC, Amsterdam, Netherlands;

${ }^{6}$ GlaxoSmithKline, Stevenage, United Kingdom

Background: T-cells are thought to be key players in the initiation and progression 